importance and will doubtless involve profound and prolonged research to determine how much of what foods old people should eat. It is for others to determine the spirit in which they eat it.

\title{
REFERENCES
}

Bransby, E. R. \& Osborne, B. (1953). Brit. 7. Nutr. 7, 160.

Fuld, H. \& Robinson, K. V. (1953). Lancet, 265, 860.

Ministry of Agriculture, Fisheries and Food: National Food Survey Committee. (1959). Domestic Food Consumption and Expenditure, 1957. London: H.M. Stationery Office.

National Assistance Board. (1958). Annual Report. London: H.M. Stationery Office.

\section{The clinical medicine of old age}

\section{By Eluned Woodford-Williams, Department of Medicine and Geriatric Medicine, The General Hospital, Sunderland}

If the relative increase in the percentage of old people in the community continues, geriatric medicine will in future occupy more and more of the time of both general practitioner and consultant. For many years it had been the custom to accept the disabilities of the elderly because of a subconscious belief that they were really incurable. The more energetic clinicians concentrated on schemes of occupational therapy and rehabilitation often with a fair degree of success but always the price in human effort and material cost was very high in relation to results and these centres of activity remained the exception rather than the rule.

In this country, mainly owing to the pioneer work of Amulree, Exton-Smith \& Crockett (195 I), Warren (1943), Howell (r943), Cosin (r953), (the late E. B.) Brooke $\&$ Wetenhall (1949) and Olbrich, Ferguson, Robson \& Stewart (1950), during the last decade there has been a revolutionary change in the medical care of the elderly. These workers showed that the most efficient and, therefore, the cheapest, quickest and easiest way to rehabilitate the elderly patient is to diagnose his disability and treat it according to regular scientific medical principles before applying the techniques of physiotherapy. The very simplicity of the idea has been a difficulty because people have been unable to realize its fundamental importance. So my first point is that geriatrics is not rehabilitation or social medicine, but a part of medical science relating to the health of the ageing, and the aged, including not only problems of disease in later life, but also the complex phenomena of normal senescence, that is, a special application of general clinical medicine.

There are special difficulties in practising general medicine among the aged. During a long life these patients have often accumulated several diseases and many scars. One of the basic principles of medicine is to try to fit all the symptoms and signs into one diagnosis, but this device derives from experience among the young, it is a device that will lead into, rather than away from, error among the aged. Here we accept that some symptoms and signs are due to one disease, some to another 
and some may be due to two or more diseases simultaneously. In addition, a symptom or sign arising from one disease may be modified by intercurrent disease. Add to all this the habit of old people of rambling on when giving the history of their illness, of forgetting parts of it, and then filling the gaps from their imagination, and add again, the characteristic silent onset of disease in the elderly, with symptoms so scanty that disease may be well advanced before medical aid is demanded, and it will be clear that diagnosis in the aged is diagnosis in the young plus something.

We find the same sort of differences when we turn to treatment. Here the central fact is that the homeostatic mechanisms of the aged organism are less effective, the reaction to stress is slow and feeble, and the vital organs have diminished reserves of function owing to previous disease, which will vary from patient to patient. Because of these difficulties no standard method of treatment is applicable in the aged, the effects on each individual of changes of function due to previous and concomitant disease must first be considered. Greater accuracy in prescribing is also needed because the margin of safety is reduced by the diminished response to stress. Lack of rapid progress easily discourages the elderly patient; treatment, therefore, has to be applied with more vigour and optimism. It is difficulties such as these that have been responsible for the neglect of this branch of medicine in the past, but for those who have seen through the mists of prejudice and tradition, it is a field which has been a challenge to their knowledge, accuracy and enthusiasm.

There are certain differences in the frequency of morbid entities in all age groups. In the aged degenerative diseases of the heart, arteries, and bones and joints, form the largest groups. Malignant disease and diseases of endocrine origin come next. Furthermore in the aged, environmental factors, especially the social, frequently precipitate the breakdown in health.

Degenerative changes may be found at any age, but usually commence in the third decade, and become the main cause of ill-health after the sixth decade. Of all degenerative changes, that occurring in the inner layers of the walls of arteries is by far the most important, being responsible for such conditions as coronary thrombosis, strokes, and gangrene of the limbs. This degeneration, known variously as atheroma or atherosclerosis, consists of the deposition of lipids in the subintimal layer, and is associated with thrombus formation in the intima. Which comes first is still a matter for argument, but it is becoming increasingly accepted that the state of nutrition is important in the aetiology.

On the basis that the basal metabolic rate is reduced and activity diminished in the aged, the calorie requirement in the elderly is said to be less than in youth. Observation, however, shows that old people in good health will eat as much as they are given. Gsell (1958), investigating the dietary habits of healthy aged Swiss peasants who continue to work into old age, noted that they have as high a calorie intake as younger men. Furthermore, Widdowson \& McCance (I955) compared the calorie intake in six starved young men and six starved old men from Wuppertal Camp. They showed that even the starved old men of 80 tolerated for 8 weeks without any ill-effects daily diets yielding $5600-6000 \mathrm{kcal}$. 
Overnutrition, however, undoubtedly plays a role in increasing the disabilities of later life. The obese are not only more likely to suffer from atherosclerosis, but also from osteoarthritis, diabetes mellitus, gall-bladder disease, herniae and varicose veins. All these conditions appear in middle life and contribute to premature old age. According to figures of the Metropolitan Life Insurance Company (1942, 1943), there is a higher death rate in overweight men, and the risk is greater at an earlier age in men than in women, whose mortality peak occurs at a later age. The higher death rates are in the markedly obese as opposed to the moderately obese. Furthermore, obesity, by reducing mobility, creates a vicious circle which leads to further weight increase. Unhappiness and loneliness, with overeating to relieve emotional tension, must not be forgotten as a predisposing factor in the development of obesity, particularly in elderly women (Fisk, I948). To this is added diminished endocrine function, and in men, lack of occupation. Treatment of obesity in the elderly is rarely successful because of the difficulty of re-educating the old with lifelong habits, but those who succeed in losing weight are likely to live longer, perhaps by several years (Dublin, 1953). Vital statistics suggest that if cancer could be cured the expectation of life would increase by 2 years, whereas elimination of obesity would prolong life expectation by 4 years. It would seem desirable that any elderly person who is $10 \%$ over standard weight for height should reduce his calorie intake.

The relationship of dietary fat to atherosclerosis and coronary thrombosis has recently received much attention. A raised plasma cholesterol tends to be associated with atherosclerosis, but plasma cholesterol does not vary with alterations in dietary cholesterol unless these are extreme (Keys, 1952). There is, however, a positive correlation between plasma cholesterol and total dietary fat, particularly that of animal origin (Snapper, r94I; Keys \& Anderson, 1955). According to Keys \& Anderson (I955) it is the total fat or proportion of total calories supplied by fats that has a major effect on serum cholesterol as age advances. He believes that this relationship has an important effect on the incidence of atherosclerosis, and this view is supported by the increased mortality from degenerative heart disease in countries where fat consumption is highest. Sinclair (1959) considers that the increased incidence of atherosclerosis in civilized countries is due to increased consumption of saturated fat at the expense of unsaturated fatty acids.

Undernutrition even these days is still commonly found among the aged, particularly in women over 78 who live alone, and in widowers and bachelors, in a wider age range. Hobson \& Pemberton (I955) found $20 \%$ of elderly patients living at home undernourished, and Fuld \& Robinson (1953) reported the admission of thirty-nine cases of severe malnutrition in 17 months to Newsham Hospital, Liverpool. The majority of cases admitted to hospital with undernutrition fall into the age range $78-85$ and live alone. In younger subjects who live alone, malnutrition is usually found in patients suffering from such conditions as Parkinsonism or advanced degrees of arthritis, probably because limitation of mobility leads to difficulties in the preparation of meals.

Scurvy, due to vitamin C deficiency, is not so rare as is generally supposed; during the past 12 months four cases of frank scurvy were admitted to the Department of 
Medicine and Geriatric Medicine, Sunderland, three men and one woman, all over the age of 75 ; none had been diagnosed before admission. Subclinical scurvy may be even more common but there is unfortunately no quick routine test for it, and it is thus liable to be overlooked.

Prolonged stress of any sort and particularly stress caused by death of a life partner contributes to subnutrition in elderly patients, I have encountered rapid loss of weight in patients after removal from their old homes in the slums to new housing estates. Fear of isolation in the elderly is even greater than their fear of death, and may result in loss of interest precipitating anorexia, mental confusion, and withdrawal, which in turn weakens resistance to physical disease processes and leads to malnutrition for which treatment in hospital may be needed. The elderly patient admitted to hospital suddenly finds that he is receiving more attention, consideration and sympathy than he has known for years. It is not surprising if he sometimes clings to his disability so that the threat of being thrown out into the cold wide world is postponed. Complementary to this reaction is that of his relatives who do all they can to prevent his return into their warm family circle, an attitude so aptly described by Rudd (1959) as 'elder rejection'. This strong trend towards hospitalization of the aged results in an overfilling of beds, and an overflowing into facilities intended for other purposes.

Isolation, poverty, and the increased social mobility of the younger generation today also influence the chances of an old person's becoming a charge on the Mental Health Services (Roth, I959). There is no doubt too, that such exogenous factors are responsible for the higher suicide rate among the elderly. The suicide rate has fallen in all Western countries in the past decade except in the age groups over 65 . The everincreasing cost of hospital accommodation and the danger of silting up of the whole service with partially treated, physically or mentally disabled, elderly patients was really the force which created modern geriatrics and the new approach to mental health.

The geriatrician must, if he is to cope with the problem with the limited facilities available to him, keep a sharp watch on the social side of his work. He must co-operate with the health authorities and voluntary organizations concerned with the welfare of the aged, and know in detail all the welfare services that are available, their applicability to a specific patient and the proper methods of bringing them into action. He must be aware of the possible social stresses which may be the real reasons for a request for admission to hospital masquerading as physical disease. He must be prepared to interview endless streams of relatives to try if possible to teach them their obligations towards a parent. This social side of the work is often not very congenial to the doctor, mainly because he has not met it in his training. He must face it, however, or else his 'pure' scientific medicine will die in a hospital full of 'cured' patients who cannot be discharged and who prevent any new patients from being admitted. By careful balancing of clinical medicine with concern for the social background it is possible to deal with the needs of the aged sick with much less hospital accommodation than has been previously thought necessary. 
There is one more activity which should be found in a geriatric unit, and that is research. Research into the nature of the ageing process is at a very early stage. Whenever we have set out to investigate a body function we have always had to begin by assessing what is the normal level of that function in the aged. It is most difficult to be sure that a given aged person is normal. Often more time must be spent on making sure that he is suitable for inclusion in the control group, than is spent on the actual assessment of the function under investigation. How little do we know of the cause of the very common complaint of weakness found particularly in those over the age of 75 (Sheldon, I948)? Is it due to disease, perhaps an expression of myocardial failure, or is it due to the process of ageing? The fact that it is associated with muscular wasting which begins in early middle life and steadily progresses thereafter suggests that it may reflect the general decline in lean body mass as age advances (Olbrich, Woodford-Williams \& Attwood, 1957).

The general lack of adaptability of old age when associated with fatigue leads to nutritional deficiencies which further accelerate the physical decline. There are as yet no means of measuring these deficiencies accurately, and a great deal more work is required before it will be possible to say that this patient is malnourished and the other overfed. We must attempt to define the exact factors in the diet which are abnormal, and even the degree of abnormality in each factor. It is only on the basis of this exact assessment of the case that efficient therapy can be prescribed. Experimental evidence on which to base reliable standards of nutrition in the elderly is still insufficient. Departments of geriatric medicine, with the large number of patients available to them have a unique opportunity to contribute to our knowledge and to the welfare of future generations. They should be encouraged to undertake research particularly into developing measures for prevention of degenerative processes and thus in the words of Descartes' 'We might be free of an infinity of maladies both of body and mind and even of the infirmities of old age if we had sufficient knowledge of their cause and remedies...'

\section{REFERENCES}

Amulree, Lord, Exton-Smith, A. N. \& Crockett, G. S. (195 r). Lancet, 260, 123.

Brooke, E. B. \& Wetenhall, J. P. (1949). Brit. med. F. ii, 49 r.

Cosin, L. Z. (1953). In Physical Medicine and Rehabilitation. [B. Kiernander, editor.] Oxford: Blackwell Scientific Publications.

Dublin, L. I. (1953). New Engl. F. Med. 248, 97 1.

Fisk, R. (1948). Nord. Med. 40, 1974.

Fuld, H. \& Robinson, K. V. (1953). Lancet, 265, 860.

Gsell, D. (1958). Gerontologia, 2, $32 \mathrm{I}$.

Hobson, W. \& Pemberton, J. (1955). The Health of the Elderly at Home. London: Butterworth and Co.

Howell, T. H. (1943). Post Grad. Med. Y. 19, no. 210.

Keys, A, (1952), Circulation, 5, 115.

Keys, A. \& Anderson, J. 'T. (1955). In Symposium on Atherosclerosis. Publication no. 338, National Academy of Sciences, Washington.

Metropolitan Life Insurance Company. (1942). Statist. Bull. Metrop. Life Insce Co. no. 23, p. 6.

Metropolitan Life Insurance Company, (r943). Statist. Bull. Metrop. Life Insce Co. no. 24, p. 6.

Olbrich, O., Ferguson, M. H., Robson, J. S. \& Stewart, C. P. (1950). Edinb. med. F. 57, 117.

Olbrich, O., Woodford-Williams, E. \& Attwood, E. C. (1957). Report of the Fourth Congress of the International Association of Gerontology, vol. 2, p. 387.

Roth, M. (1959). Brit. med. $₹$. ii, 298.

Rudd, T. (1959). Gerontologia Clinica, 1, 209. 
Sheldon, J. H. (1948). The Social Medicine of Old Age. Oxford: University Press.

Sinclair, H. M. (1955). In Old Age in the Modern World. (Report of the Third Congress of the International Association of Gerontology, London, 1954), p. 106. London: Livingstone.

Sinclair, H. M. (1959). Gerontologia Clinica, I, 33 .

Snapper, I. (I94I). Chinese Lessons to Western Medicine. New York: Interscience Publishers Inc.

Warren, M. W. (1943). Brit. med. F. ii, 822.

Widdowson, E. M. \& McCance, R. A. (I955). In Old Age in the Modern World (Report of the Third Congress of the International Association of Gerontology, London, 1954), p. 113 . London: Livingstone.

\title{
Afternoon Session
}

\author{
Chairman : Professor R. E. TUNBRIDGE, O.B.E., M.D., M.Sc., F.R.C.P., \\ Department of Medicine, The General Infirmary, Leeds I
}

\section{Nutrition and longevity in animals}

By A. Comfort, Nuffield Research Fellow in Gerontology, Department of Zoology, University College, London, W.C.I

The rate at which the mortality of animals increases with age, and consequently their life span, can be altered nutritionally in two main ways - by a large number of factors, including specific deficiencies and poisons, general malnutrition, and surfeit, which will kill them prematurely; and by a few dietary manoeuvres which affect the rate of development, and consequently the duration of the life cycle as a whole.

These effects are not always separable; most often they co-exist. For practical purposes the survival curve of an animal that undergoes actuarial ageing can usually be considered as a plateau of 'adult vigour' followed by a more or less steep decline centred about the 'specific age', or modal age of adult death: factors which alter the slope of the initial plateau or cause it to crumble away are those that produce 'premature death', though factors that alter its length and displace the specific age relative to the origin alter the 'life-span' or rate of ageing-though the distinction is difficult to make in real instances and breaks down in extremes, e.g. total deprivation of food, severe poisoning. A more practical distinction is that though it is extremely easy to kill animals prematurely by dietetic means there are relatively few ways of making them live unusually long, and it is these that are of special interest to experimental gerontology.

\section{Invertebrates}

The life cycle of many invertebrates can be lengthened in some or all of its stages by the giving of an amount of food less than that which produces maximal growth and development. The exceptions are chiefly animals or stages which draw heavily on stored reserves. In general, larvae and adults which show continued cell multiplication respond to moderate dietary restriction by lengthening the life cycle, but imagoes and adults of fixed cell number can more often be kept alive by replacement of reserves, or by reduction of activity or egg-laying which tend to exhaust them. 